\title{
Los despliegues geoestratégicos de la militarización estadounidense en el sistema mundial: transformaciones territoriales y producción estratégica del espacio de la posguerra al siglo XXI
}

\section{The Geostrategic Deployments of US Militarization in the World System: Territorial Transformations and the Strategic Production of Space from the Postwar to the 21st Century}

\author{
Cesari Irwing Rico BECERRA \\ Facultad de Ciencias Políticas y Sociales \\ Universidad Nacional Autónoma de México \\ México
}

\section{Resumen}

La presencia militar de Estados Unidos en el sistema mundial ha dejado a su paso toda una geografía política de la militarización, representada por un imperio de bases y asentamientos militares en espacios estratégicos. Desde el final de la Segunda Guerra Mundial, estas instalaciones no solamente han cumplido el papel de resguardar los intereses nacionales de Estados Unidos en el mundo y de actuar en favor de su posición como superpotencia, sino que han coadyuvado a la producción estratégica de un espacio global a través de la articulación fragmentaria de las distintas territorialidades producidas por estas bases, las cuales se han valido de una producción del sistema mundial en diferentes escalas. En el presente artículo, se buscará analizar el papel que estos despliegues militares han tenido en la producción del espacio dominante, tanto en una escala local a través de las transformaciones territoriales perpetradas por las bases militares en los distintos sitios de acogida, como en una escala global, a través de la articulación de estas bases con otras instancias del poder hegemónico (políticas, económicas, y militares, etc.), fomentando una globalización de la violencia radical en los cuerpos sociales a través de estos ejercicios de poder estratégico y produciendo, así, una nueva geografía de la militarización mundial para el siglo XXI.

Palabras clave: militarización, hegemonía, despliegue geoestratégico, bases militares, espacio dominante, Estados Unidos 


\begin{abstract}
The American military presence in the world system has left in its wake the entire political geography of militarization, represented by an empire of military bases and settlements in strategic spaces. Since the end of World War II, military facilities have not fulfilled the role of safeguarding the United States' national interests in the world, nor acting in favor of its position as a superpower. However, they have contributed to the strategic production of a global space through the fragmentary articulation of the different territorialities produced by these bases, which have availed themselves of the world system's production on different scales. In this article, we analyze the role of military deployments in the production of the dominant space, both on a local scale, through the socio-territorial transformations perpetrated by the army bases in the different reception sites, and on a global scale, through the articulation of these bases with other instances of hegemonic power (political, economic, and military), promoting the globalization of radical violence in social bodies through these exercises of strategic management and thus producing a new geography of world militarization for the 21 st Century.
\end{abstract}

Keywords: militarization, hegemony, geostrategic deployment, military bases, dominant space, United States

\title{
Introducción
}

El ejercicio del poder de la hegemonía estadounidense resulta de una combinación articulada entre sus capacidades políticas, económico-financieras, militares, culturales, ideológicas y científico-tecnológicas, que le han permitido a este sujeto consolidarse como la superpotencia más poderosa de toda la historia mundial. Como todo sistema complejo, la hegemonía de Estados Unidos funciona a través de la articulación de sus distintas capacidades en un modo de vida que se enquista y reproduce en las relaciones sociales básicas, fundiéndose con la modernidad occidental y dando pie a la existencia de aquello que Bolívar Echeverría (2008) denominaba como la modernidad americana, por la cual la modernidad imperante en la escala global ha adquirido rasgos distintivos de un modo de vida estadounidense que abre las posibilidades a una producción capitalista sin límites. Así, la hegemonía estadounidense se ha configurado por una razón de estado representada por las instituciones gubernamentales, los intereses nacionales y los sentimientos patriotas de su poder mundial, a la par de una razón de mercado que enarbola los intereses, despliegues y representaciones propias de una élite corporativa que, desde una posición más privilegiada, ha dirigido buena parte de las acciones de esta hegemonía mundial, consolidando a Estados Unidos como un Estado corporativo (Orozco Alcántar, 2001) en el cual la expansión política y territorial de la seguridad nacional siempre ha venido acompañada de una expansión y securitización de los intereses económicos, comerciales y financieros. 


\section{$10 \square$ LOS DESPLIEGUES GEOESTRATÉGICOS DE LA MILITARIZACIÓN ESTADOUNIDENSE}

Sin embargo, todos los elementos que conforman el ejercicio del poder hegemónico estadounidense han dependido, en última instancia, de profundos y sistemáticos procesos de militarización que no solamente han coadyuvado al aseguramiento de los intereses nacionales y corporativos alrededor del mundo sino que, a través de su presencia y enquistamiento territorial, han participado activamente como agentes de la producción estratégica del espacio — en todas las escalas - de la hegemonía mundial estadounidense. Esta militarización comenzó gestándose desde los primeros pasos de la expansión territorial estadounidense en contra de las agrupaciones nativas del territorio norteamericano y continuó a través de los distintos diseños geopolíticos que moldearían la espacialidad dominante del poder estadounidense en los siglos XIX y XX, hasta llegar a la configuración de una geografía planetaria de la militarización, habilitada por la hegemonía misma.

En el presente artículo se buscará analizar el papel que la militarización de Estados Unidos ha tenido en la producción del espacio dominante, a través del despliegue estratégico de sus bases militares en el siglo xxI. Para ello, se analizarán algunas de las principales representaciones territoriales del despliegue geoestratégico mundial, enfatizando el papel de bases militares que, por su importancia estratégica en el siglo XXI, se han convertido en enclaves geopolíticos de la hegemonía estadounidense. La metodología utilizada para la presente investigación partió del análisis de la militarización como proceso sociohistórico que ha coadyuvado a la producción de espacios, sujetos e imaginarios colectivos, los cuales han abonado en la reproducción y ampliación de la hegemonía mundial en sus distintas escalas. Para ello, en un primer momento se analizarán la hegemonía y la militarización como elementos centrales de la dominación estadounidense, así como los despliegues del poder estratégico que habilita la producción de un espacio dominante en escala global. Posteriormente, se presenta una reflexión sobre las bases militares como despliegues estratégicos de esta hegemonía, para concluir con un análisis sobre las transformaciones de la militarización mundial en el siglo XXI, pasando revista a las principales estrategias de dominación en las regiones globales. Con ello, el objetivo que la presente reflexión persigue es trascender las perspectivas realistas y tradicionales de la militarización como simple elemento de coerción para el mantenimiento del orden social dominante, para establecer una visión amplia de la militarización como proceso de producción socioespacial de consensos y formas de entendimiento de lo real, así como de sistemas territoriales propios de la hegemonía mundial de Estados Unidos.

\section{Hegemonía y militarización en el ejercicio de la dominación estadounidense}

Para comprender el rol de superpotencia que juega Estados Unidos en la actualidad, así como el peso específico de sus diseños geopolíticos y estrategias de militarización planetaria, es necesario hacer ciertas consideraciones conceptuales para el tratamiento 
de la hegemonía como sistema de dominación. La hegemonía debe concebirse como una compleja red de relaciones de poder que no sólo son impuestas sobre la sociedad, sino que encuentran dentro de ésta los canales y correas de reproducción para la constitución de cierta visión del mundo a partir de elementos simbólicos e inmateriales como la cultura, el lenguaje, la religión, la ideología (Gramsci, 1999: 247). Estas condiciones de reproducción varían de acuerdo con el espacio y el tiempo, creando sistemas sémicos y objetivos de dominación que determinan ordenamientos sociales y producciones espaciales dominantes.

En este sentido, la construcción de la hegemonía requiere de consensos sociales que permitan un reconocimiento del orden social dominante a través de las prácticas mismas de la vida cotidiana y son los espacios vividos, las representaciones de los espacios y los espacios representados algunas de las correas de transmisión que permiten la existencia de estos consensos. De acuerdo con Ana Esther Ceceña (2004):

La hegemonía no puede ser circunscrita al poder económico o militar, aunque éstos formen parte de los argumentos de construcción de los discursos de verdad. El poderío militar y la organización económica, para ser eficaces, deben convencer de su infalibilidad y de su inmanencia, pero deben estar también integrados a una visión de mundo capaz de brindar una explicación coherente en todos los campos, incluso en el de la vida cotidiana. En la capacidad para universalizar la propia concepción de mundo, que obnubile la perspectiva de un mundo pensado sobre otras bases (haciéndolo aparecer en el mejor de los casos como deseable, pero imposible), está el soporte de la dominación. (39-40)

Por lo tanto, la producción de regímenes de verdad llevada a cabo por la hegemonía no solamente requiere de la generación de mecanismos de coerción que actúen a favor del orden dominante cuando éste comienza a ser cuestionado y retado, sino que los mecanismos de coerción deben formar parte del consenso mismo y, a la vez, deben ser capaces de producir una visión socialmente aceptada a través de la creación de representaciones e imágenes que los proyecten como infalibles y absolutos (aunque no lo sean), como forma de aseguramiento de la reproducción de la hegemonía en todas las escalas posibles.

La militarización es uno de los procesos sociales estratégicos que han perseguido estos objetivos. Si bien para Michael Mann (2013) esta implica "la organización social de la violencia letal, la cual es concentrada, contenida, movilizada y operada por instituciones y sujetos específicos con la legitimidad y legalidad necesaria para su ejercicio" (1-2), en realidad ésta comprende procesos sociales, espaciales y estratégicos que van mucho más allá. Como proceso complejo, la militarización implica la circulación, movilización, operación y enquistamiento territorial de tropas, soldados, armamento, transporte, telecomunicaciones, operaciones especiales e infraestructura necesaria para el aseguramiento de ciertos intereses particulares, pero cuya acción rebasa el ámbito meramente militar y trasciende a todas las esferas sociales a través del ejercicio de relaciones de poder, violencia, vigilancia y control, las cuales impactan directamente 


\section{$12 \square$ LOS DESPLIEGUES GEOESTRATÉGICOS DE LA MILITARIZACIÓN ESTADOUNIDENSE}

en la producción de cuerpos, sujetos, sociedades y espacios, generando elementos de territorialización particulares de cada sitio ocupado, al tiempo que son articulados con un ordenamiento dominante de relaciones sociales propias de una planeación estratégica de amplio espectro.

Luego entonces, la militarización como proceso de espacialidad al que hacemos referencia no se limita únicamente a su uso tradicional, el cual contempla la imposición o control de los militares sobre los civiles como dos esferas sociales separadas, en la cual los primeros se conciben como sujetos apolíticos que sólo cumplen un deber, sino que se comprende a la militarización como un complejo de procesos de disciplinamiento social y producción espacial, cuyo ejercicio juega un papel crucial en los mecanismos de dominación hegemónica en escala global. En ese sentido, la militarización no debe comprenderse como un elemento accesorio para la producción y reproducción de la hegemonía mundial, sino que se convierte en uno de sus procesos medulares. Así, el capitalismo histórico siempre ha venido acompañado de múltiples procesos de militarización, cuyo objetivo ha sido permitir una articulación logística de los distintos fragmentos territoriales que componen su espacialidad global. La militarización "se vuelve un signo de las relaciones capitalistas a nivel mundial, porque es a través de ella que la sociedad se ordena y racionaliza en sus procesos y relaciones, adoptando formas organizativas netamente militarizadas, como en el ámbito de la organización y división del trabajo, las formas jerárquicas dentro y fuera del ámbito productivo, la uniformización de actividades sociales" (Herrera, 2012:17-18).

En este sentido la hegemonía estadounidense ha aprovechado a la militarización como un proceso estratégico para la consolidación de sus proyecciones como sujeto hegemónico, así como para la reproducción ampliada del sistema capitalista que la acompaña. En una escala mundial, el concepto de hegemonía hace referencia a dos ámbitos interrelacionados entre sí: 1) el referente a la reproducción de las relaciones sociales productoras del ordenamiento dominante y 2) el de la competencia entre los distintos sujetos del sistema mundial, los cuales buscan articular la organización de las relaciones de dominio en este ordenamiento (Ceceña, 2004). En este orden, la posición hegemónica de Estados Unidos es resultado del control de las modalidades internas de funcionamiento del sistema capitalista mundial en el ámbito de la competencia dado que, desde mediados del siglo xx, este sujeto histórico se ha convertido en el actor más capaz de imponer su modernidad sobre las otras modernidades en pugna, así como sus diseños geopolíticos y estrategias globales para la instauración de un ordenamiento, jerarquización y articulación de sus propios intereses hacia la armonización de la conflictividad mundial a su favor.

Esta armonización de intereses y de la conflictividad mundial ha estado guiada, de manera constante, por la militarización como forma material de preservación de la seguridad internacional de Estados Unidos y del mundo en su conjunto, lo que le ha permitido consolidar tanto una espacialidad global, como su hegemonía mundial a través de la producción de un contexto mundial altamente militarizado. Así, la militarización deberá observarse como un elemento clave - y no accesorio- en el marco del patrón de acumulación capitalista en la actualidad, pues éste juega un papel central 
en el ordenamiento social dominante de la hegemonía mundial, pues "la militarización y el recurso de la guerra - interna o externa - son el elemento sustancial para la reproducción del patrón de acumulación neoliberal que se construye sobre el despojo y el conservadurismo político. La violencia y el temor son consustanciales a la dominación neoliberal" (Rodríguez Rejas, 2017: 19-20).

No obstante, analizar el componente militar del poder nacional estadounidense implica la observación de los puntos clave en los cuales este despliegue militar se ha enquistado, para comprender las formas en que los diseños geopolíticos de la hegemonía estadounidense han logrado la producción de la espacialidad mundial antes mencionada. En ese sentido, lo militar en el ejercicio de la hegemonía estadounidense no deberá ser concebido únicamente como las formas objetivas y concretas de dominación a través de la fuerza llevadas a cabo por aparatos militares sobre la sociedad civil, sino como un mecanismo muy complejo de relaciones de poder que definen, a través de sus distintas representaciones y espacios, estructuras de disciplinamiento social a partir de formas concretas de producción de sujetos sociales y territorialidades concretas.

\section{Las bases militares y el despliegue estratégico del siglo $\mathrm{xx}$}

El siglo xx fue denominado por Henry Luce como el siglo americano, debido al inmenso aumento de las posibilidades económicas, políticas y militares de Estados Unidos para definir el ordenamiento geopolítico del siglo. A partir de 1945, a pesar de la existencia de un competidor estratégico de gran importancia como la Unión Soviética, Estados Unidos logró consolidarse como la superpotencia más importante de la historia, llevando así su influencia en todos los ámbitos de la política internacional a un nivel absoluto, tanto por la capacidad de su sistema político para adaptarse a los cambios mundiales, como por el idealismo pragmático que inspiraría a su política exterior en tal periodo (Fuzi Aizpurúa, 1999: 84).

Sin embargo, la segunda mitad del siglo xx fue también el momento en el que la militarización estadounidense comenzó a desplegarse con mucha mayor fuerza, a través del asentamiento de bases militares en territorios extranjeros que resultaban estratégicos para el diseño geopolítico de la pugna bipolar contra Unión Soviética, asentando así un imperio de bases militares que convertiría a Estados Unidos en la potencia militar con mayor presencia en el mundo de toda la historia. Con el dogma de la democracia y el idealismo pragmático que Estados Unidos impulsó durante estos años, las condiciones materiales y objetivas que permitieron el mantenimiento y reproducción de su hegemonía se sustentaron en el gran despliegue de bases militares realizado a partir de la Segunda Guerra Mundial. Como se expresará a continuación, de acuerdo con David Vine (2015a),

La profusión sin precedentes de bases militares estadounidenses que surgieron de la Segunda Guerra Mundial, sin embargo, representó un cambio cuantitativo y cualitativo 


\section{$14 \square$ LOS DESPLIEGUES GEOESTRATÉGICOS DE LA MILITARIZACIÓN ESTADOUNIDENSE}

en la naturaleza del poder estadounidense, transformando la relación del país con el resto del mundo. Para el final de la guerra, el tamaño, el alcance geográfico y el número total de bases de Estados Unidos se han expandido de manera espectacular. Nunca hubo tantas tropas estadounidenses permanentemente estacionadas en el extranjero. Nunca, los mandos militares estadounidenses habían pensado que la defensa nacional requería el despliegue permanente de fuerza militar tan lejos de las fronteras de los Estados Unidos. Después de la Segunda Guerra Mundial, Estados Unidos ordenó una presencia militar global sin igual, sin precedentes por cualquier pueblo, nación o imperio anterior en la historia. (18)

Es así como el fin de la Segunda Guerra Mundial llevó a la definición de un nuevo mapa geopolítico que constituiría al mundo en esta época. En 1946, George Kennan (encargado de negocios en Unión Soviética) publicó el artículo "Las fuentes de la conducta soviética", identificando en la URSS un potencial enemigo contrario a todas las ideas, valores, intereses y objetivos de Estados Unidos en el mundo. Asimismo, Winston Churchill afirmaría que "desde Szczecin en el Báltico, hasta Trieste en el Adriático, un telón de acero divide en dos el continente europeo" (O’Thuatail, Dalby y Routledge, 1998). Posteriormente en marzo de 1947, como respuesta a la guerra civil griega y a la posible influencia soviética sobre Turquía, Truman afirmó que debe ser la política de Estados Unidos apoyar a personas libres que están resistiendo atentados de sometimiento por parte de minorías armadas en Grecia, o por presiones del exterior, como Turquía.

Es en este contexto que Estados Unidos inaugura un diseño geopolítico para consolidar una zona de influencia en torno a su propio cinturón de seguridad a través del asentamiento de bases militares, el cual se proyectaba desde el estrecho de Bering hasta Hawái, luego hasta las islas Galápagos, la Isla de Pascua y cruza el Canal de Magallanes hasta Las Malvinas, de allí ascendiendo hasta el centro del Atlántico en las Islas Azores extendiéndose hasta Islandia, regresando por el norte polar hasta el Estrecho de Bering. Este diseño es conocido como el diseño de la contención, y su objetivo fue asegurar los intereses estadounidenses en su territorio y en los espacios estratégicos que configuraban su zona de influencia, su zona de seguridad y sus alianzas geopolíticas. Una vez asegurado este cinturón, se debería buscar la expansión hegemónica hacia otras latitudes, creando un rimland militarizado cuyo principal objetivo era contener el avance socialista al resto del mundo (Valdés-Ugalde, 2007). Así, las alianzas y bases militares ocuparon una posición preponderante en el nuevo ordenamiento, sirviendo como cabezas de puente cuyo objetivo estratégico era mantener a Eurasia como un espacio abierto para la entrada de las fuerzas militares estadounidenses, como en el resto del mundo, manteniendo el espacio libre de la influencia socialista y fundando un imperio de las bases militares por el cual Estados Unidos se ha mantenido hasta el día de hoy como el sujeto colectivo con mayor cantidad de asentamientos geoestratégicos en el mundo. De acuerdo con Chalmers Johnson (2004), 
Durante la Guerra Fría, la doctrina militar estadounidense sostenía que las bases militares en el extranjero tenían cuatro misiones. Debían proyectar el poder militar convencional en áreas de preocupación para los Estados Unidos; prepararse, si era necesario, para una guerra nuclear; servir como "cables trampa" que garantizan una respuesta estadounidense a un ataque (particularmente en "puntos calientes" divididos como Alemania y Corea del Sur); y funcionan como símbolos del poder estadounidense. (151)

No obstante, con la implosión de la Unión Soviética y el desmantelamiento de la Guerra Fría, la presencia militar estadounidense en territorios extranjeros ha perdido legitimidad de causa, lo que los ha llevado a buscar nuevas justificaciones para el mantenimiento de su presencia global, desde cuestiones relativas a intervenciones humanitarias, operaciones de desarme de estados enemigos, protección frente amenazas asimétricas como el terrorismo y el narcotráfico, entre muchas otras. Es así como las bases militares de Estados Unidos siguen cumpliendo objetivos altamente estratégicos, tales como:

\begin{abstract}
Mantener una preponderancia militar absoluta sobre el resto del mundo, una tarea que incluye la vigilancia imperial para garantizar que ninguna parte del imperio se salga de la correa; espiar las comunicaciones de ciudadanos, aliados y enemigos por igual, a menudo aparentemente solo para demostrar que ningún ámbito de privacidad es inmune a las capacidades tecnológicas de nuestro gobierno; intentando controlar tantas fuentes de petróleo como sea posible [...] proporcionando trabajo e ingresos para el complejo militar-industrial (como, por ejemplo, en las ganancias exorbitantes que Halliburton ha extraído); y asegurar que los miembros de las fuerzas armadas y sus familias vivan cómodamente mientras sirven en el extranjero. (Johnson, 2004: 51-52)
\end{abstract}

Como se mencionó anteriormente, las bases militares no solamente cumplen un papel relativo a operaciones militares, armamentistas y tecnológicas propias de la defensa bélica de los intereses nacionales estadounidenses, sino que estos asentamientos militares en el exterior se han convertido en nudosidades altamente relevantes en la producción de sistemas territoriales locales, produciendo todo un espacio público a su alrededor a partir de la transformación de la vida cotidiana del lugar en donde se enquistan y articulando estos lugares con una escala global del espacio dominante a favor de la hegemonía estadounidense. De esta manera, las bases militares que en un principio se establecieron para el control de un enemigo geoestratégico en escala global han producido una serie de transformaciones socioespaciales de gran importancia en los lugares donde se han asentado, transformando así las relaciones de la vida social en estos espacios y produciendo una artificialidad que se enquista en la cotidianidad de los espacios y funciona como correa de transmisión de la misma hegemonía. Esto permite hoy que Estados Unidos cuente con un aproximado de 800 bases militares en más de 70 países alrededor del mundo. Los principales territorios extranjeros con asentamientos militares estadounidenses son los siguientes (Tabla 1): 
Tabla 1

Bases militares de EUA por región y país en 2015

\begin{tabular}{|c|l|l|c|}
\hline No. & \multicolumn{1}{|c|}{ Región } & País destacado & Número de bases \\
\hline 1 & Europa & Alemania & 174 \\
\hline 2 & Asia Pacífico & Japón & 113 \\
\hline 3 & Asia Pacífico & Corea del Sur & 83 \\
\hline 4 & Europa & Italia & 50 \\
\hline 5 & Asia Pacífico & Guam & 47 \\
\hline 6 & América Latina y Gran Caribe & Puerto Rico & 37 \\
\hline
\end{tabular}

Fuente: David Vine (2015b: 6-7)

En este entramado se visibiliza la geopolítica estadounidense seguida por ocho décadas, más allá de la capacidad del sistema político. En su libro Base Nation, David Vine (2015b) describe la producción espacial en los alrededores de la base militar estadounidense en Guantánamo, Cuba. De acuerdo con el autor, desde una colina en la estación de la base de Guantánamo, es posible observar las avenidas (todas con nombres en inglés), las casas y los jardines propios de un típico barrio californiano, así como la presencia de negocios de comida rápida como McDonald's, Subway o Pizza Hut alrededor de ellas. Esta espacialidad producida genera la idea de una burbuja de Estados Unidos presente en la isla, la cual está destinada al consumo, esparcimiento y desarrollo de las y los estadounidenses presentes en la base, pero que impacta también a las relaciones locales de los habitantes de la ciudad de Guantánamo a través de una serie de representaciones sociales que pueden observar, pero a las cuales no pueden acceder (Vine, 2015b: 1-3).

Estas transformaciones territoriales que Vine identifica en Guantánamo pueden rastrearse en muchos de los asentamientos territoriales estadounidenses, tales como la base de Camp Lemonieer en Yibuti, o la base de Futenma en Okinawa, Japón - espacios en donde las dinámicas territoriales alrededor de las bases han transformado profundamente el espacio vivido en función de los intereses hegemónicos mundiales, despertando así protestas y movilizaciones tanto a favor del abandono de las tropas estadounidenses de los territorios, como en contra del mismo-. Esto da muestra del papel estratégico que tienen las bases militares en los distintos territorios en los que se despliegan, concentrando una serie de misiones propias de la seguridad internacional de Estados Unidos, así como misiones particulares que surgen en la proyección local de su establecimiento. En su obra, Chalmers Johnson recupera una declaración del Comité de Relaciones Exteriores del Senado estadounidense, el cual menciona que

Una vez que se establece una base estadounidense en el extranjero, adquiere vida propia. Las misiones originales pueden quedar desactualizadas, pero se desarrollan nuevas misiones, no solo con la intención de mantener en funcionamiento la instalación, sino a menudo para ampliarla. Dentro de los departamentos gubernamentales 
más directamente interesados - Estado y Defensa - encontramos poca iniciativa para reducir o eliminar cualquiera de estas instalaciones en el extranjero. (Johnson, 2004: 152)

En ese sentido, las bases militares de Estados Unidos deben comprenderse como nudosidades en la producción de sistemas territoriales en favor de la dominación hegemónica; incluso algunas pueden operar como centros que constituyen sus propias marginalidades: la producción capitalista del espacio crece exponencialmente a través de esquemas y diseños de militarización global. Es por ello que las bases militares resultan tan importantes para la hegemonía estadounidense, por lo que las Secretarías de Estado y Defensa se han negado sistemáticamente al desmantelamiento de las mismas a pesar del enorme gasto público que su mantenimiento conlleva. Por el contrario, han permitido que el Pentágono genere estrategias de contención de las protestas sociales alrededor de las mismas, como en Puerto Rico o en Okinawa, y busquen mecanismos para regresar a aquellos territorios que a lo largo del tiempo han tenido que abandonar, tales como las bases desmanteladas en Filipinas, Taiwán, Grecia y España. Con ello, Estados Unidos ha creado a lo largo de la segunda mitad del siglo xx una verdadera geografía de la militarización en escala global.

\section{Transformaciones en el despliegue estratégico en el siglo xxı: hacia una nueva geografía de la militarización mundial}

En el siglo xxı la primacía de lo militar en los asuntos globales no ha perdido vigencia con respecto a los años de la Guerra Fría, sino que su reproducción y espacialización se ha rearticulado de un campo propio de la competencia hegemónica hacia el ámbito de la reproducción social de la misma. Esto puede verse reflejado en las reflexiones de José William Vesentini (2004), quien apunta la existencia de un redireccionamiento del poder militar en los siguientes términos:

En primer lugar, existiría un redireccionamiento de la producción e investigación bélica, que dejaría de lado en énfasis en los medios de destrucción en masa [...] para enfatizar en las nuevas tecnologías de precisión [...] En segundo lugar, existe una transición en el entendimiento de la defensa, que deja de lado la amenaza del enemigo para pasar a una condición "preventiva" [...] En tercer lugar, ha cambiado la concepción del soldado. Tanto en Estados Unidos como en muchos otros países no existe más un alistamiento obligatorio, sino un compromiso voluntario o incluso una disputa sobre el mercado de trabajo por profesionales altamente calificados (ingenieros, analistas de sistemas, físicos, médicos, sociólogos, psicólogos). (87-89)

Con base en estas transformaciones es posible argumentar que la militarización global del mundo contemporáneo tiene más que ver con un tránsito del poder militar del ámbito de la competencia entre estados, gobiernos y fuerzas armadas hacia el ámbito 
de la reproducción social de la hegemonía, a partir de la expansión de las revoluciones técnico-científicas del proceso de globalización actual hacia los medios militares, en donde los flujos de información, comunicación y articulación logística global cobran una importancia superlativa en la configuración militar del mundo.

De este modo, en los últimos años, Estados Unidos ha impulsado la instauración de un nuevo diseño geopolítico para la hegemonía mundial cuyo objetivo es la producción de un nuevo paradigma de espacialidad que permita asegurar la reproducción, rearticulación y ampliación de su hegemonía a través de la regulación, vigilancia y disciplinamiento de las sociedades mundiales. Para ello, el despliegue militar efectuado por Estados Unidos en los primeros 20 años del presente siglo ha buscado abarcar en un panóptico global todos los espacios estratégicos del sistema mundial a través de una serie de despliegues estratégicos que toman en cuenta a los comandos militares, las bases, flotas, Lily-pads, comunicaciones estratégicas, fuerzas especiales y demás dispositivos de las fuerzas armadas estadounidenses, así como de otras instancias supuestamente autónomas del poder militar, pero que forman parte del poder estratégico de la hegemonía mundial (Bitar, 2016).

Estas nuevas expresiones de la hegemonía mundial se traducen en múltiples representaciones materiales, las cuales persiguen una articulación de los fragmentos que componen al espacio global, así como la creación de cercos que imposibiliten a cualquier sujeto o resistencia a recuperar territorios o espacios estratégicos cuya pérdida pueda significar una amenaza para la hegemonía mundial. Una de estas representaciones materiales implica la utilización de la militarización como proceso regulador, entendido como la organización social de la violencia letal, la cual es concentrada, contenida, movilizada y operada por instituciones y sujetos específicos con la legitimidad y legalidad necesaria para su ejercicio.

Esta militarización se ha visto multiplicada a través de una guerra permanente que ha moldeado las primeras dos décadas del siglo xxI, por la cual se ha desplegado un aparato de militarización mundial sin precedentes que ha buscado la consolidación de una dominación de espectro completo (Joint Chiefs of Staff, 2000) cuyo objetivo ha sido producir un espacio global a partir del mecanismo disciplinado de la militarización en todas las escalas. Así, bases militares y posicionamientos estratégicos de diversa índole a lo largo del planeta funcionan de manera articulada bajo un discurso de seguridad que sostiene la bandera de la defensa de la paz, pero que en realidad se vale de la guerra y la violencia propias del ordenamiento geopolítico internacional.

Aunado a ello, podemos encontrar una gran diversidad de formas en las que los flujos de información que configuran a los espacios y territorios funcionan como elementos que coadyuvan a la espacialidad de la dominación hegemónica, tales como los espacios urbanos y los grandes procesos de cercamiento urbano a partir de la construcción de edificaciones y conjuntos habitacionales, los territorios de importancia estratégica para la acumulación y el despojo, la construcción de presas, canales, ductos, como sitios de renta monopólica, que afectan directamente a comunidades a través de procesos de despojo y violencia. A consideración de Ceceña (2013), 
Se sistematizó, con detalle científico, cada uno de los niveles o espacios del espectro donde pudiera perpetrarse un potencial enemigo. Espacio exterior, espacio atmosférico, aguas, superficie terrestre, bajo tierra; espacios públicos y privados que deberían ser penetrados mediante mecanismos panópticos (cámaras en las esquinas, en los bancos y oficinas, chips espías, sistemas de datos centralizados, etc.). Vida cotidiana, vida productiva, pensamiento y acción. Barrios populares con políticas diferenciadas de las de los barrios de clase media o clase alta, estratificación competitiva, transporte, dotación de servicios, etc., todos puntos de observación y manejo de poblaciones. (6-7)

De esta manera, el mapa conceptual estratégico de la dominación estadounidense en el siglo XXI se configura en torno a la idea de aprovechar una oportunidad histórica, la cual se configura como irrepetible, para la consolidación de una hegemonía sin límites para los Estados Unidos. A partir de la conflictividad mundial imperante, pero al mismo tiempo de una relativa supremacía geoestratégica, "Estados Unidos rediseña sus metas, sus espacios, modifica sus mecanismos, genera exigencias tecnológicas, recompone los equilibrios entre trabajos de inteligencia, de persuasión y de combate, redefine los puntos críticos y los esquemas de aproximación" (Ceceña, 2013: 5) a partir de una dominación de espectro completo sobre los cuerpos, los sujetos y los espacios en escala global. Dentro de esa supremacía, las prioridades y objetivos en la agenda geopolítica estadounidense encuentran su expresión material en la presencia militar alrededor del mundo, presencia que tiene como objetivo principal evitar el surgimiento de cualquier amenaza, tanto en el ámbito de la competencia como en la reproducción social, en las distintas regiones que componen al espectro planetario.

Por ello, el control y comando del espacio global resulta imprescindible para el mantenimiento y reproducción de la hegemonía estadounidense en el siglo xxI, y las prioridades de la agenda geopolítica estadounidense tienden al mantenimiento de dicho control. Los intereses geopolíticos de la rearticulación de la hegemonía deben entenderse, al mismo tiempo, en una escala global, regional y local, a través de las distintas territorializaciones en cada una de las regiones del mundo, las cuales resultan de singular importancia para los intereses hegemónicos estadounidenses.

Hasta el año 2015 se tenía conocimiento de 5055 posiciones militares de Estados Unidos en territorios extranjeros, incluyendo Lily-pads y bases rotativas. De todas ellas, las bases más representativas se encuentran en los territorios nacionales de Alemania, Italia, Japón, Honduras, Burkina Faso, Irak, Tailandia y Filipinas, como se vio en la Tabla 1. A partir de ello, es posible identificar una mayor presencia en territorios estratégicos, ya sea por la existencia de recursos, movimientos de resistencia, posiciones geoestratégicas que definen una espacialidad articulada a través de los enquistamientos militares alrededor del globo. Tal militarización, entonces, no resulta ajena a intereses geopolíticos, sino que responde a la conflictividad global que pone en riesgo los mismos despliegues estratégicos de la hegemonía mundial.

En su obra El nuevo mapa del Pentágono, Thomas P. M. Barnett (2004) delinea la nueva geografía política del Pentágono a través de la configuración de distintas regiones 


\section{$20 \square$ LOS DESPLIEGUES GEOESTRATÉGICOS DE LA MILITARIZACIÓN ESTADOUNIDENSE}

estratégicas para el mantenimiento de la supremacía estadounidense, dentro de los cuales se encontraba la denominada "brecha crítica". Los países de esta región son aquellos en donde las sociedades han configurado movimientos de resistencia en contra de las determinaciones geopolíticas de la hegemonía mundial, por lo que son calificados de "inestables e ingobernables" (Barnett, 2004). Esta delimitación corresponde a territorios del denominado Sur Global, pertenecientes a las regiones de América Latina, África y Eurasia, regiones donde los despliegues geoestratégicos se han enquistado de manera más profunda.

En América Latina, la necesidad de militarización obedece a una incesante y constante inmersión con el fin de mantener su "zona de seguridad" bajo el dominio hegemónico. Al ser la región inmediatamente contigua a las fronteras estadounidenses, las relaciones de dominación y los dispositivos del ejercicio del poder históricamente han sido muy claras, desde la puesta en marcha de la Doctrina Monroe, por lo que ha sido tremendamente estratégica para la hegemonía mundial, representando el primer eslabón en la cadena del expansionismo territorial estadounidense, después de la consolidación en territorio norteamericano. Así, la región ha sido subordinada a las estrategias geopolíticas de Estados Unidos y a sus pretensiones de dominación hegemónica, pues resultaba imprescindible para la exportación de dichas estrategias hacia otras latitudes que el sistema estadounidense se enquistara profundamente en las estructuras de vida de su zona de seguridad, pues,

\footnotetext{
En realidad, América ha sido un territorio en ocupación por parte de Estados Unidos desde que terminó la conquista del Oeste y no se saciaba la avidez del capitalismo renovado que crecía en sus tierras. Emblemáticamente, la doctrina Monroe expresaba el futuro que desde ahí se trazaba para el continente, pero sus mecanismos han sido múltiples, pasando por la Alianza para el Progreso, los planes de desarrollo, los créditos atados de la sustitución de importaciones y la deuda externa, los tratados de libre comercio, los ajustes estructurales y el Tratado Interamericano de Asistencia Recíproca (TIAR), entre otros. (Ceceña, 2006: 24)
}

La presencia de asentamientos militares de Estados Unidos en los territorios latinoamericanos ha sido amplia — más que en cualquier otra región en el mundo- En la actualidad, la militarización estadounidense en América Latina busca responder a la necesidad creciente de asegurarse el uso irrestricto de los territorios y recursos del continente, lo cual ha generado un cada vez mayor surgimiento de movimientos sociales y resistencias populares en defensa del territorio, los cuales repudian directamente proyectos estratégicos de la hegemonía mundial, y comenzaron a significar un importante obstáculo para la supremacía estadounidense en el mundo, pero sobre todo en América Latina (Ceceña, 2006).

Por otro lado, la llegada al poder de gobiernos populares en Centro y Suramérica representaron un bloque geopolítico contrario, al menos en discurso y en ciertos elementos, al ordenamiento geopolítico estadounidense, sumándose a la resistencia política que Cuba había configurado desde el triunfo de su revolución en 1959. Se desencadenó 
en diversos países del sur del continente - Venezuela, Bolivia, Ecuador, Uruguay, República Dominicana, entre otros - el triunfo de gobiernos de izquierda que buscaron contrarrestar la influencia de la hegemonía estadounidense a través de la unidad regional y la autonomía económica a través de un mercado común que les permitiera crear un bloque favorable para América Latina y la transformación radical del poder de mando de los ejércitos latinoamericanos, dejando de lado las instrucciones de Washington, para configurar una milicia nacionalista en favor de los intereses de los países de América del Sur (Rodríguez Rejas, 2017).

Debido a ello, desde inicios del siglo xxi la presencia militar de Estados Unidos en América Latina se redobló; las distintas instalaciones militares impuestas por Estados Unidos a partir de 2001 están respondiendo a los acontecimientos políticos que cuestionaron su papel como amo de la región latinoamericana a finales del siglo xx. Se configura lo que Rodríguez Rejas (2017) denomina la "norteamericanización de la seguridad", es decir, la articulación de todas las agendas de seguridad nacional de la región, bajo un proyecto hegemónico dictado desde Washington. Ejemplos de ello pueden identificarse con los siguientes elementos:

- La existencia de 76 bases militares de Estados Unidos en América Latina, cuya presencia contempla los territorios de Honduras, Panamá, Colombia, Perú, Paraguay, Aruba y Curaçao, El Salvador, Costa Rica, Cuba.

- La articulación de la logística militar regional, ejercida por el Comando Sur, el cual funge como representación directa del Pentágono en la región, operatividad logística de la militarización latinoamericana.

- La reactivación de la Cuarta Flota en 2008, dotándosele del control de todos los buques, aeronaves navales y submarinos que operan en el Caribe, Centro y Sudamérica.

- La puesta en marcha de proyectos estratégicos de penetración militar ya sea directa o indirecta, tales como el Plan Colombia (1999), ASPAN (2005), Iniciativa Mérida (2008) y el Acuerdo Estados Unidos-Colombia (2009). (Rodríguez Sumano, 2012).

Luego entonces, resulta muy claro que la militarización de América no solamente se ha mantenido, sino que ha aumentado y se ha recrudecido en los últimos años, a través de la apertura de nuevas bases militares en la región, así como la permanente actividad de la cuarta flota, la cual circunda las costas suramericanas. Asimismo, las alianzas y supuestos esfuerzos conjuntos de seguridad regional han aumentado la presencia militar en la región y se han consolidado como dispositivos del ejercicio de un claro poder de dominación hegemónica.

Del otro lado del hemisferio sur, la región africana se ha configurado cada vez más como un espacio estratégico para la reproducción de los intereses hegemónicos estadounidenses, basados en recursos energéticos en el golfo de Guinea y en el control de fronteras para evitar que sirvan de base logística para grupos terroristas, así como 


\section{$22 \square$ LOS DESPLIEGUES GEOESTRATÉGICOS DE LA MILITARIZACIÓN ESTADOUNIDENSE}

frenar el avance de intereses de China. Pese a que, en repetidas ocasiones, el Departamento de Defensa ha mencionado que la presencia militar en África es menor, durante el presente siglo se ha desplegado una importante red de instalaciones militares sobre el continente, muchas de ellas disfrazadas de proyectos en favor del desarrollo y los derechos humanos de las sociedades africanas, pues la constelación de bases militares estadounidenses incluye 34 asentamientos repartidos por todo el continente, con altas concentraciones en el norte y el oeste, así como en el Cuerno de África. Estas regiones, como es lógico, también han visto numerosos ataques con aviones no tripulados de EU, así como redadas de comandos de bajo perfil en los últimos años (Turse, 2018). La militarización en esta región está diseñada para el aseguramiento del acceso a espacios estratégicos, sobre todo aquellos en los que existen reservas de minerales estratégicos y demás recursos, en un continente caracterizado por amplias extensiones de tierra y poca infraestructura. Así, en los últimos años Estados Unidos ha invertido en la apertura de diversas bases y centros militares en el continente, tales como la base de Camp Lemmonier en Yibuti, la cual cuenta con uno de los mayores complejos de aviones no tripulados del mundo, y del cual se han conducido operaciones tanto a Yemen como a Somalia; asimismo, recientemente se ha anunciado la creación de un complejo más grande que el de Yibuti, pero en Níger (Turse, 2018). Esta base militar es la más extensa en territorio africano, y sirve como base del Comando regional estadounidense. Su importancia actual recae en el hecho de que, en el mismo perímetro espacial, tanto China como Francia mantienen bases militares para resguardo de sus intereses en África y Medio Oriente. De acuerdo con el portal oficial:

La base de Camp Lemonieer proporciona, opera y mantiene un servicio superior en apoyo de la preparación para el combate y la seguridad de los barcos, aeronaves, destacamentos y personal [...] es una instalación liderada por la Marina de los EE. UU. Operada por el Comandante de la Región de la Marina de Europa, África y el Sudoeste de Asia a través de las Fuerzas Navales de Estados Unidos y el Comando Africano [...] El Campamento cuenta con aproximadamente 4000 efectivos militares y civiles de las fuerzas armadas y afines de los Estados Unidos y contratistas del Departamento de Defensa de los Estados Unidos. Además, la base proporciona empleo a aproximadamente 100 trabajadores locales y de terceros países. (CNIC, 2015)

La base se encuentra colocada en las cercanías del Estrecho de Bab-el Mandeb, espacio que representa una prioridad estratégica para Estados Unidos, debido a su posición geopolítica privilegiada que enlaza el mar Rojo con el golfo de Adén, separando el Cuerno de África, en el continente africano de la península arábiga, lo que conforma una zona de intensa competencia geoestratégica para las grandes potencias regionales, tales como China y las potencias europeas. Debido a la importancia estratégica de la base militar, así como al posicionamiento geopolítico de Yibuti para el control de África subsahariana, las inversiones en la base militar son muy importantes, generando profundas transformaciones territoriales para la comunidad existente alrededor de esta instalación, la cual se convirtió en la principal fuente de empleo para la sociedad 
yibutiana. Sin embargo, la planeación estratégica de la base ha realizado recortes presupuestales para la base militar. En junio de 2013, el ejército estadounidense firmó un contrato de \$35 millones de dólares con el proveedor de servicios Kellog Brown \& Root (KBR), lo que implicó la reducción del personal africano para el apoyo de operaciones básicas (trabajos de limpieza, lavandería y servicio de alimentos) de 1200 a 600 trabajadores. Esto generó grandes protestas al exterior de la base militar exigiendo la restitución de los empleos perdidos (Vandiver, 2013). Ejemplos como este reflejan lo contradictorio de esta presencia militar en territorios extranjeros ya que, mientras en algunas regiones - particularmente en América Latina — la respuesta social puede ser muy contraria a la presencia militar estadounidense, en Yibuti la base militar es una fuente de ingresos para la comunidad local.

Por otro lado, en la parte Euroasiática del mundo, la presencia militar estadounidense encuentra una importancia estratégica mucho mayor que en las regiones anteriores. Eurasia ha sido uno de los pivotes geopolíticos de mayor importancia para la reproducción de la hegemonía mundial, uno de los centros de poder más importantes del planeta entero. Esto puede ser entendido debido a su amplia riqueza en energéticos (con las reservas probables de petróleo y gas natural más elevadas del mundo); la importancia histórico-cultural de sus territorios se ha disputado por diversos imperios y dinastías durante siglos. La presencia de espacios estratégicos de inconmensurable importancia como el Mar Mediterráneo, el Mar de China, el Estrecho de Malaca, el Estrecho de Gibraltar, entre otros espacios geográficos comunes cuya red de comunicación en torno al transporte marítimo, resulta vital para el comercio mundial (Kaplan, 2014: 13).

Por lo anterior, instalaciones militares como la base aérea de Ramstein en Alemania representan nodos ampliamente estratégicos para la presencia estadounidense en la región. Esta base militar ha sido reconocida por el uso de vehículos aéreos no tripulados o drones que no solamente han aprovechado su mirada vertical y volumétrica para el espionaje y la toma de imágenes aéreas, sino también por la presencia de transportes aéreos no tripulados con armamento letal. Ramstein representa la base aérea estadounidense más grande en territorio extranjero; en su perímetro espacial, perteneciente a la comunidad de Renania-Platinado, viven más de 54000 estadounidenses, ya sean militares, familiares o jubilados; además, esta base ofrece empleos a ciudadanos alemanes (Wagner, 2019). En los últimos años, han existido varias controversias internacionales con el gobierno alemán debido a misiones y acciones perpetradas por parte de aviones no tripulados estadounidenses proveniente de la base aérea de Ramstein, ya que varios ataques a territorios cercanos podrían haber sido comandados desde esta base aérea sin que el gobierno alemán tuviera conocimiento, por lo que organizaciones no gubernamentales en defensa de los derechos humanos han buscado el cierre total de esta base, lo cual implicaría un golpe importante a toda la geoestrategia de Estados Unidos en Eurasia.

En el otro extremo de la región, el posicionamiento estratégico de Estados Unidos en el Pacífico ha sido uno de los elementos de mayor prioridad estratégica para sus diseños geopolíticos. Es por ello que, desde muy temprano en el siglo xxI, la prioridad 


\section{$24 \square$ LOS DESPLIEGUES GEOESTRATÉGICOS DE LA MILITARIZACIÓN ESTADOUNIDENSE}

estratégica de Estados Unidos se desplazó de la parte occidental de Eurasia hacia el extremo oriental, debido a la posible conformación de una alianza estratégica entre China y Rusia derivada de la firma en 1996 de la Organización para la Cooperación de Shanghái, pues estos sujetos internacionales representaban la única posible amenaza en el ámbito de la competencia para la superpotencia estadounidense.

Las Fuerzas Armadas de Estados Unidos han mantenido, desde la Segunda Guerra Mundial, una presencia significativa en el Pacífico compuesta tanto por ejércitos de tierra, aire, mar, y los activos de marines instalados en muchos países asiáticos. Sus bases militares más importantes se encuentran en Corea del Sur y Japón. También ha establecido recientemente una presencia militar de rotación con algunos socios del Pacífico, incluyendo Filipinas y Australia. Los activos y el personal estadounidense desplegado en Hawái, Alaska y Guam también se dedican a la protección y seguridad de los intereses estadounidenses en la región. Para tales efectos, el poderío militar estadounidense se ha valido de una militarización exacerbada en la zona a través del Comando del Pacífico, el cual tiene como principal objetivo la organización, unión y logística de las Fuerzas Armadas de Estados Unidos presentes en este espacio, y funge como la representación directa del Departamento de Defensa en la región.

Su cuartel general se encuentra en Honolulú, en la isla de Oahu, Hawái, y su zona de influencia abarca el Océano Pacífico desde la Antártida hasta el oeste del Océano Ártico, abarcando las costas de la parte siberiana de Rusia, China, Mongolia, Corea del Norte, Corea del Sur, Japón, los países del Sureste Asiático y la zona Sur de Asia en la frontera occidental de India, el Océano Índico al este y al sur de la línea de India y Pakistán así como Madagascar, Australia, Nueva Zelandia y Hawái. Desde el siglo XXI, la región se ha convertido en un espacio de necesario control para la hegemonía mundial, pues de perderse la influencia en esta región, Estados Unidos perdería el control de una de las zonas más importantes para la dinámica capitalista mundial, como veremos. Aunado a todo ello, la cantidad de recursos estratégicos y las vías de comunicación que se encuentran presentes en esta región hacen de Asia Pacífico el premio geopolítico de mayor importancia y, por supuesto, la principal prioridad en materia de defensa.

La geoestrategia del despliegue militar en el Pacífico ha buscado una rearticulación espacial, la cual implica el cierre de bases tan importantes en la región como la de Futenma en Okinawa, la cual concentra el $25 \%$ del total de efectivos estadounidenses en toda la región, convirtiéndose en la base más costosa de todo el mundo (ChanletAvery y Rinhart, 2016). Ocurren nuevos posicionamientos estratégicos en la Isla de Guam y en la Isla de Darwin, Australia; se buscan innovaciones en la organización militar con diversas tecnologías — entre ellas, el surgimiento de bases rotativas - las cuales posibilitan los desplazamientos desde la base por mar en respuesta a las diversas amenazas y riesgos que se presenten en la región, reduciendo costos y aumentando los beneficios para la hegemonía mundial.

En suma, es posible identificar que el despliegue geoestratégico de las bases militares estadounidenses sobre el sistema mundial en el siglo xxı busca consolidar, mantener y 
ampliar la producción del espacio dominante en la escala global que se gestada hace más de ocho décadas, enquistándose en aquellos territorios de mayor peso estratégico, cuyo control resulta imprescindible para la reproducción global de la hegemonía.

\section{Conclusiones}

Las bases militares de Estados Unidos en el mundo siguen siendo una de las principales condicionantes de la territorialización de la hegemonía mundial en los distintos espacios. Su articulación en torno a un proyecto global las convierte en nudosidades altamente estratégicas para la reproducción socioespacial de las relaciones de poder que constituyen el espacio dominante. La hegemonía, al constituirse como un sistema de ordenamiento social compuesto por entramados de relaciones de poder que produce sujetos, imaginarios, espacios y sentidos comunes, así como relaciones sociales en todas las escalas articuladas con el capitalismo como sistema dominante, necesita de la existencia de puntos de apoyo que funcionen como el sostén material de la dominación. La hegemonía de Estados Unidos se ha sustentado en los asentamientos militares en escala global, los que habilita para la reproducción de su hegemonía.

El despliegue geoestratégico del siglo americano significó la base material idónea para la reproducción de la hegemonía en una escala ampliada, la cual permitió la articulación de los distintos fragmentos del mundo en torno a un mismo sostén rizomático de la influencia mundial de Estados Unidos durante la Guerra Fría, y que a su vez coadyuvó para la configuración de consensos sociales sobre la superioridad indiscutible de este sujeto colectivo sobre cualquier otro sujeto del sistema internacional, incluyendo a su más cercano competidor, la Unión Soviética. Las grandes transformaciones mundiales del siglo Xxi han obligado a las fuerzas armadas estadounidenses a buscar nuevas tácticas, estrategias y despliegues geoestratégicos que permitan una rearticulación de la presencia militar de la hegemonía mundial, en favor de su reproducción, ampliación y mantenimiento. Con ello, el papel de las bases militares alrededor del mundo cobró una nueva vigencia, así como un papel estratégico mucho mayor.

Los movimientos y organizaciones sociales en las distintas latitudes del planeta, la necesidad de acceder de manera irrestricta a recursos y territorios estratégicos, así como la renovación de la competencia intercapitalista por los distintos actores del sistema mundial, se han convertido en los nuevos riesgos y amenazas para la posición hegemónica de Estados Unidos en el siglo xxI. Frente a ello, los despliegues militares han buscado ampliar sus capacidades de control y disciplinamiento a través de la instauración de una dominación sobre el sistema mundial, sustentada en los despliegues del americanismo propios del siglo xx y reforzados con las grandes innovaciones tecnológicas del ámbito militar en el siglo XXI.

Por tanto, el papel de la militarización en la actualidad responde más a la necesidad de producción de espacios diferenciales de despojo y acumulación, así como fragmentos territoriales estratégicos funcionales para el capitalismo histórico en general, 


\section{$26 \square$ LOS DESPLIEGUES GEOESTRATÉGICOS DE LA MILITARIZACIÓN ESTADOUNIDENSE}

y para la supremacía estadounidense en lo particular, representando un instrumento de reforzamiento de los órdenes de dominación que sustentan su proyecto hegemónico en una arena global repleta de riesgos, amenazas y peligros para su reproducción hegemónica.

Con ello, la militarización se ha constituido históricamente como un proceso de producción socioespacial, que envuelve la configuración de imaginarios colectivos, así como de sistemas territoriales que determinan la vida cotidiana y el espacio público de distintas sociedades alrededor del mundo, articulándolas con la reproducción y ampliación de la hegemonía mundial de Estados Unidos. Así, la articulación de las transformaciones territoriales que habilitan estas bases militares en una escala local con la producción estratégica del espacio en escala global determinada por el poder infraestructural de la militarización estadounidense, configuran una geografía de la militarización mundial que representa el sostén rizomático de la hegemonía mundial en el siglo xxI, por lo que las instalaciones militares de Estados Unidos en el mundo seguirán cumpliendo un papel ampliamente estratégico en la reproducción y ampliación de la hegemonía en los años por venir.

\section{Referencias bibliográficas}

Barnett, Thomas P. M. (2004). The Pentagon's New Map. War and Peace in the Twenty First Century. Nueva York: The Berkley Publishing Group.

Bitar, Sebastian. (2016). US Military Bases, Quasi-bases, and Domestic Politics in Latin America. Nueva York: Palgrave Macmillan.

CECEÑA, Ana Esther. (2004). "Estrategias de construcción de una hegemonía sin límites". Hegemonías y emancipaciones en el siglo XXI. Buenos Aires: Consejo Latinoamericano de Ciencias Sociales

CECEÑA, Ana Esther. (2006). "Sujetizando el objeto de estudio, o de la subversión epistemológica como emancipación”. Los desafios de las emancipaciones en un contexto militarizado. Buenos Aires: Consejo Latinoamericano de Ciencias Sociales.

CECEÑA, Ana Esther. (2013). "La dominación de espectro completo sobre América". Patria, (1).

Chanlet-Avery, Emma; Rinhart, Ian. (2016). "The U.S. Military Presence in Okinawa and the Futenma Base Controversy". Congressional Research Service. Recuperado el 30 de julio de 2020 de https://fas.org/sgp/crs/row/R42645.pdf

Commander Navy Installations Command (CNIC). (2015). "Camp Lemonieer, Djibouti” (en línea). Recuperado el 30 de julio de 2020 de https://www.cnic.navy. $\mathrm{mil} /$ regions/cnreurafcent/installations/camp_lemonnier_djibouti.html

ECHEVERRíA, Bolívar. (2008). "La Modernidad Americana (claves para su comprensión)". La americanización de la modernidad. México: Biblioteca Era; CISAN, UNAM. 17-50. 
Fuzi AızPuRúA, Juan Pablo. (1999). "El siglo americano”. Cuadernos de Historia Contemporánea, 21, 83-105. https://revistas.ucm.es/index.php/CHCO/article/view/ CHCO9999110083A

Gramsci, Antonio. (1999 [1975]). Cuadernos de la cárcel, Tomo 1. Puebla: ERA; Benemérita Universidad Autónoma de Puebla.

Herrera, David. (2012). “'La política es continuación de la guerra por otros medios': hegemonía y poder en las relaciones internacionales del siglo xxI". Escenarios XXI, (13), 5-19. http://www.paginaspersonales.unam.mx/files/753/Publica_20120801193605.pdf

Johnson, Chalmers. (2004). The Sorrows of Empire. Militarism, Secrecy and the end of the Republic. Nueva York: Owl Books; Henry Holt \& Company.

Joint Chiefs of Staff. (2000). “Joint Vision 2020: America's Military—Preparing for Tomorrow”. Joint Force Quarterly. A Professional Military Journal. https://apps. dtic.mil/dtic/tr/fulltext/u2/a526044.pdf

KaPLAN, Robert. (2014). Asia's Cauldron. The South China Sea and the end of a stable Pacific. Nueva York: Random House.

Luce, Henry. (1941). The American Century. Nueva York: Farrar \& Rinehart.

Mann, Michael. (2013). The Sources of Global Power, Vol. 4: Globalizations, 19452011. Nueva York: Cambridge University Press

O'Tuathail, Geroid; Dalby, Simon; Routledge, Paul. (1998). The Geopolitics Reader. Nueva York: Routledge.

Orozco AlCÁntar, José Luis. (2001). De teólogos, pragmáticos y geopolíticos. Barcelona: Gedisa; UNAM

Rodríguez Rejas, María José. (2017). La norteamericanización de la seguridad en América Latina. México: Akal.

Rodríguez Sumano, Abelardo (Coord.). (2012). Agendas comunes y diferencias en la seguridad de América del Norte. Guadalajara: Universidad de Guadalajara; CucsH.

Turse, Nick. (2018, 1 de diciembre). "U.S. Military Says It Has a 'Light Footprint' in Africa". The Intercept (en línea). Recuperado el 30 de julio de 2020 de https:// theintercept. com/2018/12/01/u-s-military-says-it-has-a-light-footprint-in-africa-thesedocuments-show-a-vast-network-of-bases/

Valdés-UGalde, José Luis. (2007). Estados Unidos. Intervención y poder mesiánico: la Guerra Fría en Guatemala. México: cusAn; unAm.

VAndiver, John. (2013, 10 de julio). "Workers Protesting Work Force Cuts at US Base in Africa". Stars and Stripes (en línea). Recuperado el 30 de julio de 2020 de https://www.stripes.com/news/africa/workers-protesting-work-force-cuts-atus-base-in-africa-1.229711

VeSEnTINI, José William. (2004). Novas Geopolíticas. As representações do século XXI. Sao Paolo: Editora Contexto.

VINE, David. (2015a). "Where in the World Is the US Military?". Politico Magazine (en línea) Recuperado el 30 de julio de 2020 de https://www.politico.com/magazine/story/2015/06/us-military-bases-around-the-world-119321 
$28 \square$ LOS DESPLIEGUES GEOESTRATÉGICOS DE LA MILITARIZACIÓN ESTADOUNIDENSE

VIne, David. (2015b). Base Nation. How U.S. Military Bases Abroad Harm America and the World. Nueva York: Metropolitan Books.

Wagner, Jeniffer. (2019, 14 de marzo). “¿Drones de Estados Unidos parten de Ramstein?”. Deustche Welle. Actualidad/política (en línea). Recuperado el 30 de julio de 2020 de https:/www.dw.com/es/drones-de-eeuu-parten-de-ramstein/ a-47921074 